\title{
Toxic Assessment of Heavily Traffic-related Fine Particulate Matter Using an in-vivo Wild-type Caenorhabditis elegans Model
}

\author{
Meng-Ching Chung ${ }^{1}$, Kuo-Lin Huang ${ }^{*}$, Japheth L. Avelino ${ }^{2}$, Lemmuel L. Tayo ${ }^{2}$, \\ Chih-Chung Lin 1,3*, Ming-Hsien Tsai ${ }^{4}$, Sheng-Lun Lin ${ }^{5,6,7}$, Wan Nurdiyana Wan Mansor ${ }^{8,9}$, \\ Ching-Kai Su ${ }^{10}$, Sen-Ting Huang ${ }^{10}$
}

\author{
${ }^{l}$ Department of Environmental Science and Engineering, National Pingtung University of Science and Technology, Neipu, \\ Pingtung 91201, Taiwan \\ ${ }^{2}$ School of Chemical, Biological and Materials Engineering and Sciences, Mapúa University, Muralla St., Intramuros, \\ Manila 1002, Philippines \\ ${ }^{3}$ Institute of Food Safety Management, College of Agriculture, National Pingtung University of Science and Technology, \\ Pingtung 91201, Taiwan \\ ${ }^{4}$ Department of Child Care, National Pingtung University of Science and Technology, Neipu, Pingtung County 91201, Taiwan \\ ${ }^{5}$ Department of Civil Engineering and Geomatics, Cheng Shiu University, Niaosong District, Kaohsiung 83347, Taiwan \\ ${ }^{6}$ Center for Environmental Toxin and Emerging-Contaminant Research, Cheng Shiu University, Niaosong District, \\ Kaohsiung 83347, Taiwan \\ ${ }^{7}$ Super Micro Mass Research and Technology Center, Cheng Shiu University, Niaosong District, Kaohsiung 83347, Taiwan \\ ${ }^{8}$ Faculty of Ocean Engineering Technology \& Informatics, Universiti Malaysia Terengganu, 21300, Malaysia \\ ${ }^{9}$ Air Quality and Environment Research Group, Universiti Malaysia Terengganu, 21300, K. Nerus, Malaysia \\ ${ }^{10}$ Department of Internal Medicine, Kaohsiung Veterans General Hospital Pingtung Branch, Neipu, Pingtung 91245, Taiwan
}

\begin{abstract}
In association with the mortality rate due to air pollution, vehicular emitted fine particles $\left(\mathrm{PM}_{2.5}\right)$ are a threat to public health. $\mathrm{PM}_{2.5}$-induced in-vivo studies on environmental microorganisms can be used to assess the adverse impacts of $\mathrm{PM}_{2.5}$ on human health. In the present study, the toxicity of traffic-related-air-pollutant (TRAP) $\mathrm{PM}_{2.5}$ was evaluated in the animal model Caenorhabditis elegans (C. elegans) using different toxicological endpoints such as lethality, survivability (lifespan), behavioral (head thrashing and body bending), and reproduction (brood size). The TRAP PM 2.5 sample were collected in Taichung City, Taiwan from Mar 24 to April 15 in 2018. Of these 23 day samples, three samples (Days A, B, and C) were randomly selected. The results showed that no immediate lethality was observed after acute $(24 \mathrm{~h})$ exposure of the nematodes. On the other hand, sublethal endpoints of reproduction exhibited statistically significant dose-dependent reduction, although Day A and Day C did not decrease the egg-laying capability of the worms. For the neurological toxicity, it is inferred that the higher the $\mathrm{PM}_{2.5}$ concentrations, the more the adverse effects of neurobehavior (head trashing and body bending) it poses on the C. elegans. The lifespans of nematodes exposed to heavily TRAP PM 2.5 were significantly shortened compared with those of untreated ones based on survival rate. The nematodes exposed $\mathrm{PM}_{2.5}$ models not only posed potentially adverse health effects on human but also represented ecotoxic impacts on the ecosystem. In conclusion, heavy concentrations of TRAP $\mathrm{PM}_{2.5}$ significantly and severely disrupted toxicological endpoints of neurology and reproduction to $C$. elegans. TRAP $\mathrm{PM}_{2.5}$ significantly shortened the lifespan of the nematodes compared with the control. TRAP PM 2.5 might more severely influenced the specific toxic endpoints, such as lifespan and neurobehavira, in this in-vivo models compared with the reproductive endpoints.
\end{abstract}

Keywords: $\mathrm{PM}_{2.5}$; Traffic related air pollutant (TRAP); C. elegans; Lifespan; Reproduction; Locomotion.

\footnotetext{
* Corresponding author.

Tel.: +886-8-7703202 ext. 7092 or 7079 ;

Fax: $+886-8-7740256$

E-mail address: huangkl@mail.npust.edu.tw (K.L. Huang);

lincc@mail.npust.edu.tw (C.C. Lin)
}

\section{INTRODUCTION}

Ambient and indoor air pollution, the most important environmental risk to health, contributed 7 million deaths each year in the past decade (WHO, 2016). The risks that entail $\mathrm{PM}_{2.5}$ or fine particulate have threatened the mortality 
of human lives and the adverse health effects associated with $\mathrm{PM}_{2.5}$ made it as a major indicator of air particle pollution by the World Health Organization (WHO, 2005). Reports have shown that worldwide exposure to outdoor $\mathrm{PM}_{2.5}$ contributed to 4.1 million deaths connected with heart disease and stroke, lung cancer, chronic lung disease, and respiratory infections (Orru et al., 2011; HEI, 2018; Li et al., 2018; Hayes et al., 2019). The increasing epidemiological studies indicate that cardiopulmonary morbidity due to $\mathrm{PM}_{2.5}$ exposure play a part in the development of diabetes mellitus and adverse birth outcomes (Hu, 2009; Crouse et al., 2012; Kloog et al., 2012; Chen et al., 2013; Burnett et al., 2014; Zanobetti et al., 2014). $\mathrm{PM}_{2.5}$ is accountable for a substantially larger number of attributable deaths than other more well-known life behavioral risk factors such as physical inactivity, alcohol use, and high sodium intake, and it is equivalent to the attributable deaths caused by high cholesterol and high body mass index (HEI, 2018).

$\mathrm{PM}_{2.5}$ has chemical constituents such as sulfates, nitrates, and ammonium and its large surface area enable it to carry various toxic compounds such as polycyclic aromatic hydrocarbons (PAHs), black carbon, phthalates, and heavy metals (Yue et al., 2006; Labrada-Delgado et al., 2012; Jiang et al., 2019; Wang et al., 2019; Xing et al., 2020). $\mathrm{PM}_{2.5}$ can be emitted directly into the air due to anthropogenic activities or it can be formed in the atmosphere, creating secondary particles (Lu et al., 2019; Lisetskii et al., 2019). $\mathrm{PM}_{2.5}$ has also been identified as one of the major contributor in traffic-related air pollution (TRAP) (Chao et al., 2018; Xiang et al., 2019; Min et al., 2020). Motor vehicle traffic is an important source of harmful emissions of $\mathrm{PM}_{2.5}$ in the cities of developing countries (Kinney et al., 2011; Brown et al., 2019). According to Kinney et al., (2011), daytime concentrations of $\mathrm{PM}_{2.5}$ at the sites adjacent to roadways ranged from $50.7-128.7 \mu \mathrm{g} \mathrm{m}^{-3}$ which were higher than WHO's 24-hour average guideline $\left(25 \mu \mathrm{g} \mathrm{m} \mathrm{m}^{-3}\right.$ ) (WHO, 2005). A similar study conducted by Brown et al., (2019) also reported elevated $\mathrm{PM}_{2.5}$ concentrations at the near-road sampling sites in Denver and Indianapolis. It is indicative that traffic emissions contribute to $\mathrm{PM}_{2.5}$ levels in the environment and may also cause health damage to people exposed to it. Upon inhalation, $\mathrm{PM}_{2.5}$ can readily pass through the nose filtration and then deposit at the end of the respiratory tract, consequently damaging other parts of the body through air exchange (Williams et al., 2019).

Furthermore, $\mathrm{PM}_{2.5}$ still presents significant risks to public health even at levels far below the national standards (Elliott and Copes, 2011; Fann et al., 2012). Several in-vitro and epidemiological studies showed evidences suggesting the negative health effects that airborne TRAP $\mathrm{PM}_{2.5}$ might pose to the general public. The induced exposure to $\mathrm{PM}_{2.5}$ of human lung bronchial epithelial cells (BEAS-2B) generated DNA breakage and micronucleus formation indicating that it caused oxidative stress (Oh et al., 2011). The $\mathrm{PM}_{2.5}$ induced toxicity in rat lung epithelial cells was found to be cytotoxic and it also caused severe oxidative damage to the cells (Choi et al., 2004). It was also found out that people who were exposed to TRAP $\mathrm{PM}_{2.5}$ having higher levels of proinflammatory biomarkers such as $\mathrm{TNF}-\alpha$ which is an indicator that $\mathrm{PM}_{2.5}$ from traffic sources is a significant contributing factor to the increase of systemic inflammation in humans (Brucker et al., 2013; Zhao et al., 2013; Chao et al., 2018). Additionally, a report indicated strong associations between TRAP $\mathrm{PM}_{2.5}$ exposure and adverse health effects like atopic diseases and allergic sensitization (Morgenstern et al., 2008).

The $1 \mathrm{~mm}$ long free-living soil nematode used in the animal model Caenorhabditis elegans (C. elegans) established by Sydney Brenner in 1965 plays a key role in the decomposition and nutrient cycling (Sohlenius, 1980). The C. elegans in-vivo system has been used as a model for the assessment of toxic effects of air pollutants (Zhao et al., 2014; Sun et al., 2015, 2016; Yang et al., 2016; Wu et al., 2017; Wang et al., 2018; Chung et al., 2019; Zhao et al., 2019) because it shows much advantages over other animal models: production of large number of progeny (100-200 from a single hermaphrodite), transparency, rapid life cycle (3 days), short lifespan (2-3 weeks), low cost, and easy laboratory cultivation (Brenner, 1974; Nass and Hamza, 2007). Moreover, C. elegans follows the widely accepted ethical principles, known as Three Rs (Reduction of the use of higher animals, Refinement of current techniques, and Replacement of animals with alternative methods) (Brenner, 1974).

The toxicity effects of $\mathrm{PM}_{2.5}$ have been successfully examined using the $C$. elegans animal model. Coal combustion-related $\mathrm{PM}_{2.5}$ can induce deficits in the lifespan, development, reproduction, and locomotion behavior of C. elegans by altering the expression patterns of genes related to the control of oxidative stress (Sun et al., 2015). Specifically, more severe toxicity was observed for prolonged $\mathrm{PM}_{2.5}$ exposures compared to short-term exposures (Sun et al., 2015). In addition, Sun et al. (2016) found that heavy metals such as lead, chromium, and copper in coal combustionrelated $\mathrm{PM}_{2.5}$ induced lower responses on locomotion behavior and lifespan of nematodes, and the combined exposure to these metals caused greater toxicity than single metal exposure. Similarly, Yang et al. (2016) pointed out that certain heavy metals in ambient $\mathrm{PM}_{2.5}$ possibly caused a decrease in locomotion behavior and production of intestinal reactive oxygen species (ROS) in C. elegans; moreover, the gene ( $m t l-1$ and $m t l-2$ ) encoded metallothioneins, the proteins involving in the control of stress response to heavy metals in the nematodes, were significantly expressed and could have potential key roles in regulating $\mathrm{PM}_{2.5}$ toxicity (Yang et al., 2016). More importantly, a critical finding in $C$. elegans studies is the transgenerational effects of exposure to $\mathrm{PM}_{2.5}$. Adverse effects on several toxic endpoints (e.g., reproductive function) were observed not only on the exposed nematodes but also on the later generations of $C$. elegans after exposure to traffic related air pollutants (TRAP) $\mathrm{PM}_{2.5}$, which led to the combined effects of oxidative stress, intestinal barrier damage, and abnormal defecation behavior (Zhao et al., 2014) as well as DNA damage (Wang et al., 2019). For the studies of $\mathrm{PM}_{2.5}$ toxicity in C. elegans, oxidative stress seems to be one of the primary contributing factors to $\mathrm{PM}_{2.5}$-mediated toxicity. Oxidative stress was induced via the mir-231-SMK-1-SOD3/SOD-4/CTL-3 signaling pathway after exposure of $C$. elegans to coal combustion-related $\mathrm{PM}_{2.5}$ (Wu et al., 2017) 
and the expression levels of certain antioxidant enzymes such as glutathione S-transferase (GST-4), superoxide dismutase (SOD-3), glutathione peroxidase (GSH-Px), and catalase (CAT) increased in response to the oxidative stress (Zhao et al., 2019). Currently, few studies focused on the toxic effects of TRAP $\mathrm{PM}_{2.5}$ on C. elegans models: therefore, this study aims to evaluate the toxicity responses of TRAP $\mathrm{PM}_{2.5}$ between 24 March and 15 April in 2018 in a major road in Taichung City, Taiwan. Different toxicological endpoints such as survival (lethality and lifespan), behavior or locomotion (head thrash and body bend), and reproduction (brood size) were used in the tested $C$. elegans models.

\section{METHODS}

\section{Reagents and Raw Materials}

Nematode growth medium (NGM) plates consisted of bacteriological agar and bactopeptone (Laboratories Conda, S.A., Spain) and $\mathrm{NaCl}$ (Honeywell Fluka ${ }^{\mathrm{TM}}$, New Jersey, USA) were used in this study. Additional components like $\mathrm{CaCl}_{2}, \mathrm{~K}_{2} \mathrm{HPO}_{4}$, and cholesterol were all acquired from Sigma-Aldrich (St. Loius, MO, USA), while $\mathrm{MgSO}_{4}$ was acquired from Avantor Performance Materials, Ltd. (Gyeonggi-do, South Korea). Luria-Bertani broth used as a growth medium for Escherichia coli (E. coli) was purchased from Sigma-Aldrich. The bleaching solutions utilized in the experiment were $\mathrm{NaOCl}$ (J.T. Baker, Central Valley, PA) and KOH (Duksan Pure Chemicals, Gyeonggi-do, South Korea). $\mathrm{KH}_{2} \mathrm{PO}_{4}$ obtained from Avantor Performance Materials, LLC (Radnor, PA, USA) was used for the phosphate buffer, and $\mathrm{Na}_{2} \mathrm{HPO}_{4}$ used for the M9 buffer was purchased from Honeywell Fluka ${ }^{\mathrm{TM}}$. The components of K-medium were $\mathrm{NaCl}$ (Honeywell Fluka ${ }^{\mathrm{TM}}$ ) and $\mathrm{KCl}$ (Avantor Performance Materials). All the physiological observations were made using a dissecting microscope (Olympus, SZX10, Wlatham MA, USA).

\section{Air Sampling}

The ambient $\mathrm{PM}_{2.5}$ air samples were collected from Section 4, Taiwan Avenue, Xitun District, Taichung City. The air sampling site was situated near the Tungdai air monitor site of the Environmental Protection Bureau of Taichung City Government in Tunghai University. Each air sample was collected for 24 hours during the duration from March 24 to April 15 in 2018 in Taiwan through the use of a high-volume air sampler (SIBATA HV-1000R, Japan) following the US EPA Reference Method TO9A or Taiwanese EPA NIEA A205.11C. Quartz fiber filters that had been heated at $600^{\circ} \mathrm{C}$ for $2 \mathrm{~h}$ before sampling were used to collect $\mathrm{PM}_{2.5}$ samples. Each filter paper was conditioned in an electronic desiccator before and after the sample collection for $24 \mathrm{~h}$. It was weighed using a balance with an accuracy of $0.1 \mathrm{mg}$. The loaded filters were stored in a refrigerator at $-20^{\circ} \mathrm{C}$ in the National Pingtung University of Science and Technology (NPUST) before extraction in order to limit the possible evaporation of volatile components.

\section{Sample Preparation}

Each collected air sample was extracted using a Soxhlet extractor with dichloromethane (DCM) for $24 \mathrm{~h}$. Then, the extract was eluted with $15 \mathrm{~mL}$ DCM for the acid-silica column clean-up. The eluate was concentrated to $1 \mathrm{~mL}$ then it was placed to a vial. Afterwards, it was further concentrated to near dryness via a nitrogen stream. $\mathrm{PM}_{2.5}$ was serially diluted $10 \mathrm{X}$ with $1 \%$ DMSO for the exposure concentrations. The sample's toxicity tested in the study was controlled in the organic fraction. The samples of 23-day $\mathrm{PM}_{2.5}$ samples were prepared for subsequent toxic tests. For the consideration of lifespan more than 22 days, it was decided that the three days, such as Mar 24, April 4, and April 8, were randomly selected from 23 days between Mar 24 and April 15 in 2018.

\section{Age Synchronization of C. elegans}

The wild-type N2 strain of C. elegans was gifted from the Department of Biochemistry and Molecular Biology, College of Medicine, National Cheng Kung University (Tainan, Taiwan) and it was maintained in NGM plates seeded with OP50 E. coli, which was acquired from the Bioresources Collection and Research Center (Hsinchu, Taiwan), as food and these plates were incubated at $22^{\circ} \mathrm{C}$. Then, the plates containing enough eggs and gravid nematodes were chosen and they were washed off with $\mathrm{ddH}_{2} \mathrm{O}$ and placed in a centrifuge tube. Afterwards, the gravid nematodes were lysed using the bleaching solution while the eggs remained. The bleaching method lasted for only 6 minutes in order to avoid the eggs to be killed off. Then, the eggs were obtained and placed in a petri dish containing M9 buffer and it was incubated at $22^{\circ} \mathrm{C}$ for $12-48 \mathrm{~h}$. After this period, agesynchronized L1 nematode could be produced.

\section{Acute Exposure}

The obtained L1 worms were incubated until L3 or young L4 stage. The plates were then gently washed with K-medium in order to get the worms and centrifuged at $2500 \mathrm{x} \mathrm{g}$ for 2 minutes. E. coli residues were removed by aspirating the supernatant without disturbing the pellet. Afterwards, the pellet was re-suspended in K-medium and the seeding volume (worm $\mu \mathrm{L}^{-1}$ ) was calculated by placing two aliquot $10 \mu \mathrm{L}$ on a glass slide and manually counting the worms per drop. Approximately 200 worms were seeded per well in a 12-well plate containing $1 \mathrm{~mL}$ of different exposure concentrations for each samples diluted with K-medium. Then, it was incubated at $22^{\circ} \mathrm{C}$ for $24 \mathrm{~h}$ without the presence of food.

\section{Lethality Assay}

For the lethality assay, 50 exposed worms (per exposure concentration) were transferred into an NGM plate without the presence of food. The viability was assessed by gently poking the worms using a worm picker and the nonresponsive nematodes were considered as dead. The assay was done in triplicate for all concentrations.

\section{Locomotion Assay (Head Thrashing and Body Bending)}

Head thrashing and body bending behavior were assessed in order to evaluate the motility of the nematodes exposed to different $\mathrm{PM}_{2.5}$ concentrations by placing them in a plate containing K-medium. The movement of the head of the worms and/or tail to the same side was counted as one thrash 
while the body bending was counted when the worms were able to bend its body in a C-shape. The head thrashing was counted for 1 minute and the body bend for 20 seconds. Thirty worms were assessed and triplicates were made per concentration.

\section{Reproductive Assay (Brood Size)}

The brood size or reproductive assay was done by assessing the capability of the L3 or young L4 worms to produce an egg for 4-5 days. One exposed worm is transferred in an NGM plate containing OP50 E. coli food and it was incubated at $22^{\circ} \mathrm{C}$. After every 2 days, the worms were transferred into a fresh NGM plate until the egg-laying activity ceased. The old plates with eggs were incubated and allowed to grow until L3 for easier counting of progeny. Thirty worms were evaluated for this assay.

\section{Lifespan Assay (Ageing)}

Fifty worms obtained from the acute exposure were transferred to NGM plate with food. The worms were transferred every day until the egg-laying period (4-5 days) is done. After that, there was no need to transfer the worms and their viability was assessed every day for 24 days (general lifespan of worms). Then, the worms were scored as alive, censored (lost), and dead. The effects of the different concentrations of $\mathrm{PM}_{2.5}$ samples on the lifespan of the nematodes were assessed by constructing the survival plot or Kaplan-Meier plot. Triplicate was done for each exposure concentration.

\section{Statistical Analysis}

The data of locomotion and reproduction were found to be not fulfilled normally distribution. The survival plot constructed using Kaplan-Meier were used to evaluate the effects of the $\mathrm{PM}_{2.5}$ to the ageing of the worms exposed to different exposure concentrations. The nonparametric Kruskal-Wallis $H$ and Mann-Whiney $U$ tests were utilized to compare and examine the differences of each concentration to the control. The plots for the lifespan assay were derived using the GraphPad Prism 8 (San, Diego, California, USA) while the significance for each day was defined using the Kruskal-Wallis $H$ test. The determined significant days were further tested by comparing them to the control using the Mann-Whitney $U$ test. All the statistical analyses were made through the use of Statistical Package for the Social Sciences (SPSS) version 12 (International Business Machines Corp., New York, USA).

\section{RESULTS AND DISCUSSION}

\section{Air Pollution in the Highly Heavy Traffic Area}

Fig. 1(a) shows the high 24-hour mean levels of $\mathrm{PM}_{2.5}$ at the Tungdai air monitor site from March 24 to April 15, 2018 provided from the website of Environmental Protection Bureau, Taichung City. The highest level of $\mathrm{PM}_{2.5}$ was $80 \mu \mathrm{g} \mathrm{m}^{-3}$ on April 2 at 1:00 pm and the lowest one was $11 \mu \mathrm{g} \mathrm{m}^{-3}$ on April 6 at 2:00 am. The mean with standard deviation (SD) of 24-hour mean $\mathrm{PM}_{2.5}$ for these 23 days was $39.0 \pm 3.49 \mu \mathrm{g} \mathrm{m}^{-3}$. The $\mathrm{PM}_{2.5}$ levels in this heavily traffic area during these 23 days were obviously higher than the
WHO guideline $\left(25 \mu \mathrm{g} \mathrm{m}^{-3}\right)$ and most of them exceeded TEPA standard ( $35 \mu \mathrm{g} \mathrm{m}^{-3}$ for 24-hour mean). High levels of $\mathrm{PM}_{10}$, ozone $\left(\mathrm{O}_{3}\right)$, sulfate dioxide $\left(\mathrm{SO}_{2}\right)$, nitrogen dioxide $\left(\mathrm{NO}_{2}\right)$, and carbon monoxide $(\mathrm{CO})$ were also found in the heavily TRAP area (Figs. 1(b), 2(a), and 2(d)), although the dates of highest levels for these pollutants were different. $\mathrm{PM}_{2.5}$ and $\mathrm{PM}_{10}$ were highly correlated because they are particulate phase emitted from the TRAP pollution (Fig. 1). Distributed characteristic of $\mathrm{PM}_{2.5}$ was inconsistent with those of gas phase pollutants like $\mathrm{O}_{3}, \mathrm{SO}_{2}, \mathrm{NO}_{2}$, and $\mathrm{CO}$ (Figs. 1 and 2).

\section{Lethal Effects of PM2.5 to C. elegans}

After 24-h exposure, the lethality values of different $\mathrm{PM}_{2.5}$ concentrations to the age-synchronized worms were inspected. It was observed that all the samples with different $\mathrm{PM}_{2.5}$ concentrations (Day A [March 25 2018] B [April 4 2018], and C [April 8 2018]) did not exhibit any lethal effects on the young L4 nematodes (Figs. 3(a), 3(b), and 3(c), respectively). A similar result obtained by Sun et al. (2015) who demonstrated that coal combustion related $\mathrm{PM}_{2.5}$ had no lethal effects on exposed nematodes even after prolonged exposure. Zhao et al., (2014) also found that TRAP PM 2.5 did not induce any adverse effects on the $C$. elegans after acute and prolonged exposure. One our previous report also showed no lethality for any ambient $\mathrm{PM}_{2.5}$ sample collected from rural areas including NPUST (0.00144-1440 $\left.\mathrm{mg} \mathrm{L}^{-1}\right)$ and Linluo Junior High School (0.00115-1150 $\left.\mathrm{mg} \mathrm{L}^{-1}\right)$ (Chung et al., 2019). Further tests were made in order to confirm that $\mathrm{PM}_{2.5}$ did not cause immediate mortality to the exposed nematodes. Environmental toxicants, such as TRAP $\mathrm{PM}_{2.5}$, can enter the nematode's intestines thereby affecting the intestinal cells and making them as the primary targeted organs. However, they can also be translocated into other parts of the body such as the reproductive organs and even the neurons (Nouara et al., 2013; Zhao et al., 2015). Thus, it is important to perform toxicity assay regarding the locomotion and reproduction in order to determine whether $\mathrm{PM}_{2.5}$ caused an adverse effect on the worms.

\section{Effects of TRAP PM2.5 on the Brood Size of C. elegans}

Brood size assay or the egg laying capability of the nematodes was assessed after exposure to different $\mathrm{PM}_{2.5}$ concentrations (Figs. 4(a)-4(c)). The worms exposed to 7.43, 74.3, and $743 \mathrm{~g} \mathrm{~L}^{-1}$ concentrations of Day B $\mathrm{PM}_{2.5}$ sample had a significant reduction on their brood size or their egg number; however, those exposed to Days A and C $\mathrm{PM}_{2.5}$ samples did not present any effect on their reproduction. Although this result is still unclear, further studies are necessary to identify the underlying mechanism. One our previous study also showed that high ambient $\mathrm{PM}_{2.5}$ concentration had a negative effect on the brood size of the C. elegans (Chung et al., 2019). Moreover, several studies have demonstrated the dose-dependent manner reduction of the brood size of the nematodes exposed to different toxic compounds, such as $\mathrm{PM}_{2.5}$ from coal combustion (Sun et al., 2015), cadmium (Wang et al., 2018), zearalenone (Yang et al., 2018), and silver nanomaterial (Moon et al., 2019). Hodgkin and Barnes (1991) reported that the optimum progeny of a hermaphrodite 


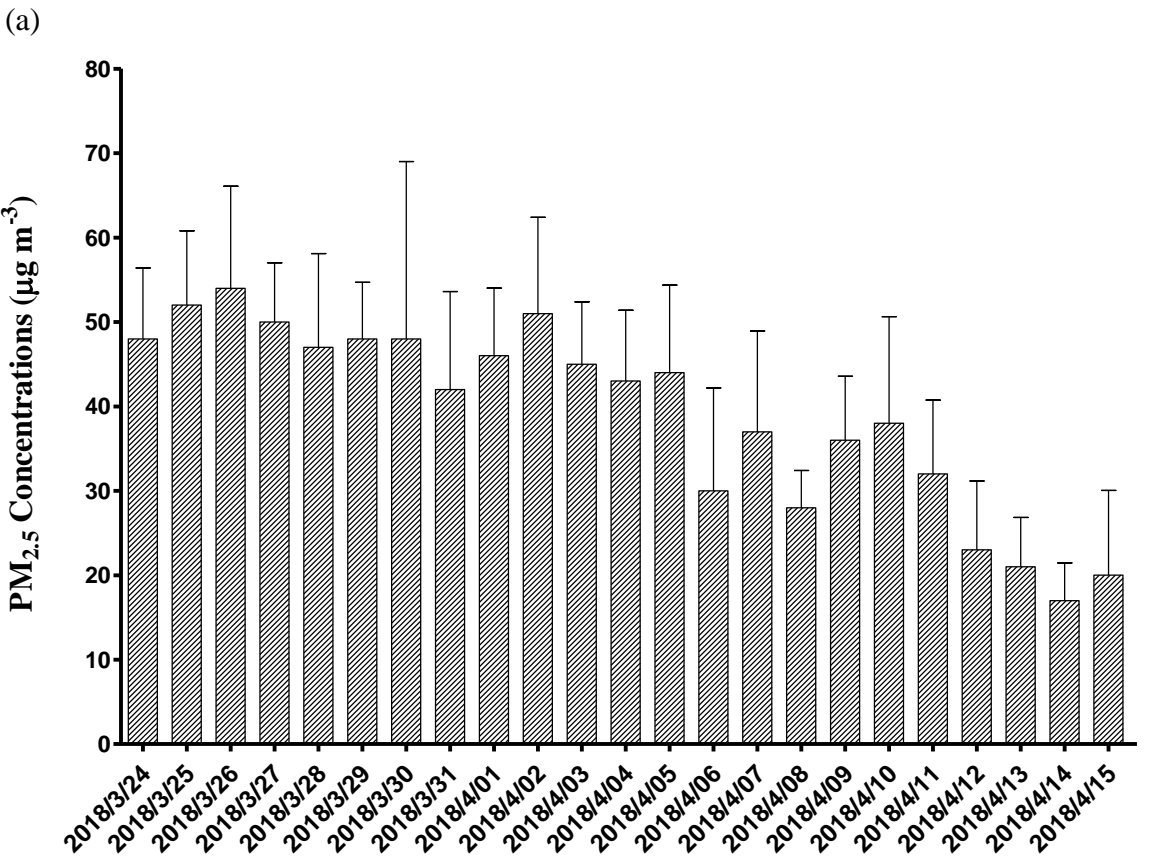

24-hour mean $\mathrm{PM}_{2.5}$ concemtrations between March 25 and April 15 in 2018.

(b)

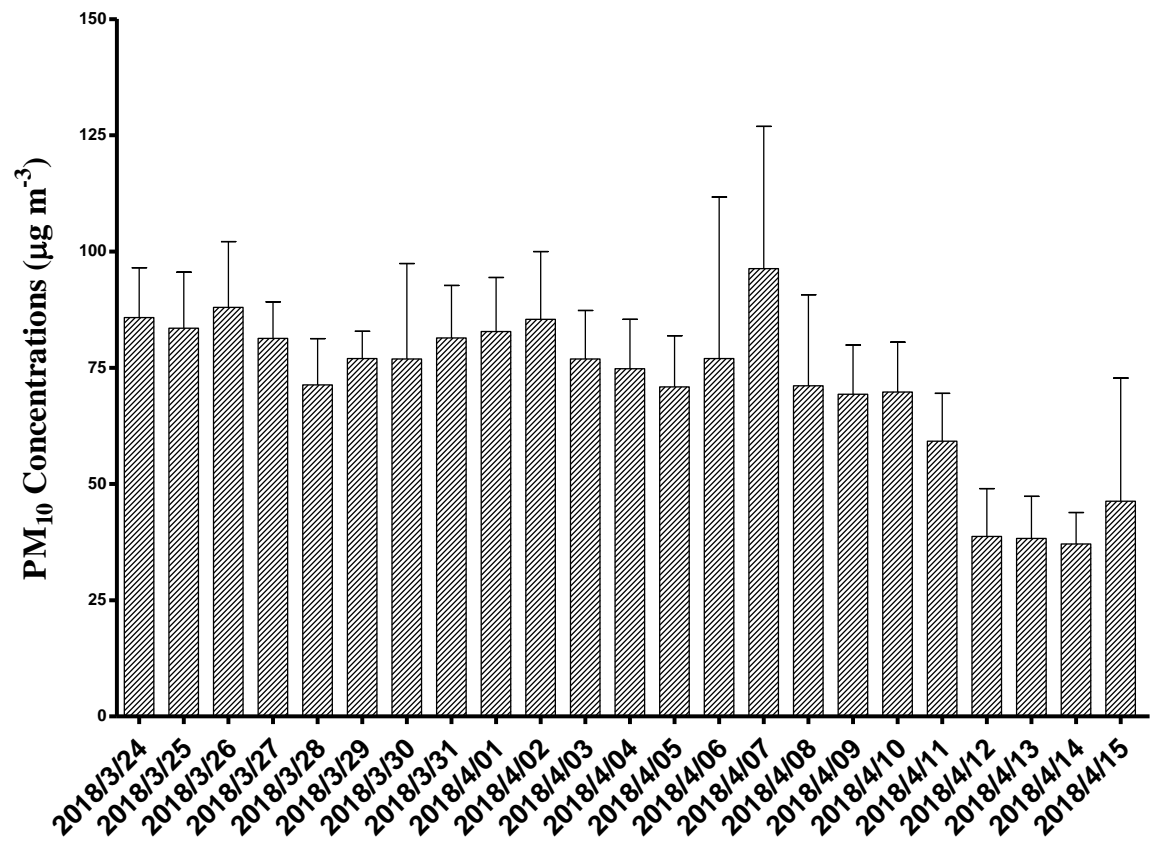

24-hour mean $\mathrm{PM}_{10}$ concemtrations between March 25 and April 15 in 2018.

Fig. 1. 24-hour mean levels of (a) $\mathrm{PM}_{2.5}$ and (b) $\mathrm{PM}_{10}$ from March 24, 2018 to April 15, 2018 in the Tungdai air monitor site.

nematode was around 300, but in one our previous report (Chung et al., 2019) and the present study, the fecundity of the $C$. elegans was far below the optimum number reported by Hodgkin and Barnes (1991). Factors such as dietary intake and temperature have been found to have correlation with the delayed and altered reproductive capabilities of the worms (McMullen et al., 2012; Petrella, 2014; El-Hajj and Newman, 2015). Wang et al. (2019) indicated that the exposure of $C$. elegans to diesel particulate matter (DPM) (a dominant $\mathrm{PM}$ in $\mathrm{PM}_{2.5}$ ) increased a significantly dosedependent matter in germ line cell apoptosis and exhibited a significantly dose-independent decrease in brood size from 0 to $100 \mu \mathrm{g} \mathrm{mL}^{-1}$. Zhao et al. (2014) revealed that $\mathrm{PM}_{2.5}$ at $100 \mathrm{mg} \mathrm{L}^{-1}$ from urban areas significantly decreased the brood size of $C$. elegans in the acute exposure scenario and those between 1.00 and $100 \mathrm{mg} \mathrm{L}^{-1}$ in the prolonged exposure 
(a)

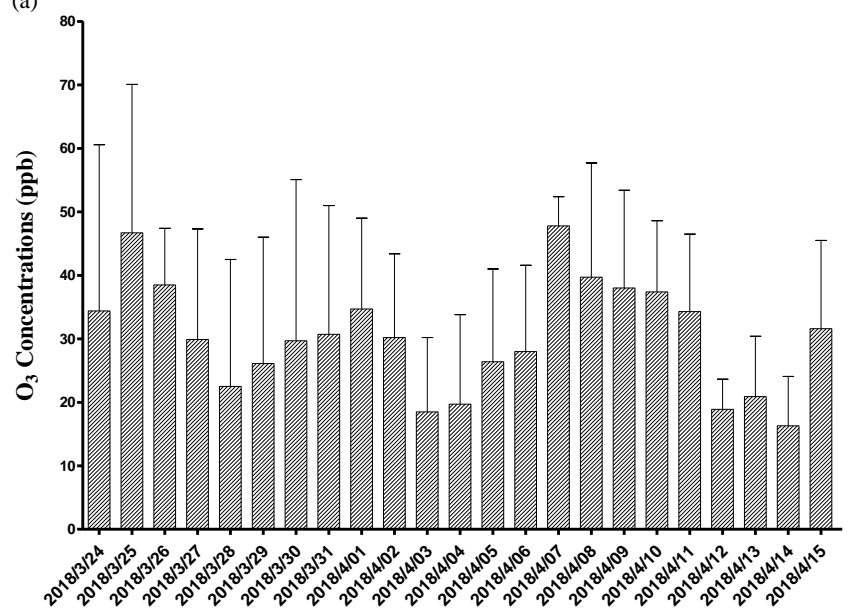

$\mathrm{O}_{3}$ concentrations from $3 / 24$ to $4 / 15$ in 2018 .

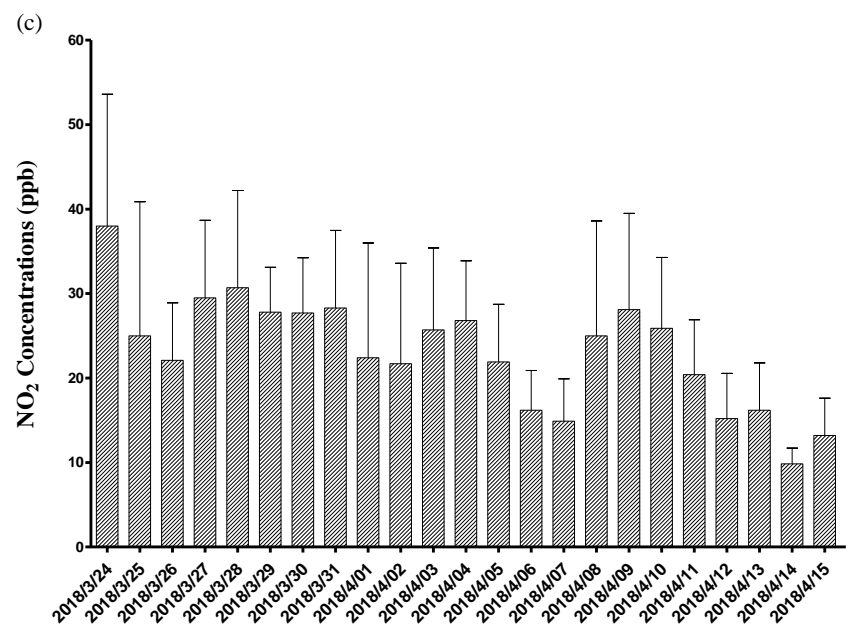

$\mathrm{NO}_{2}$ concentrations from $3 / 24$ to $4 / 15$ in 2018.

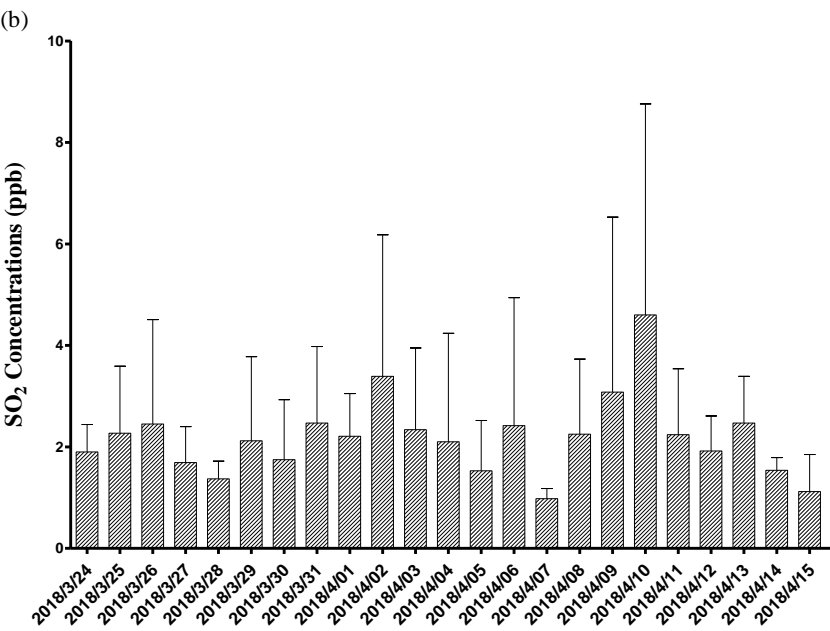

$\mathrm{SO}_{2}$ concentrations from $3 / 24$ to $4 / 15$ in 2018 .

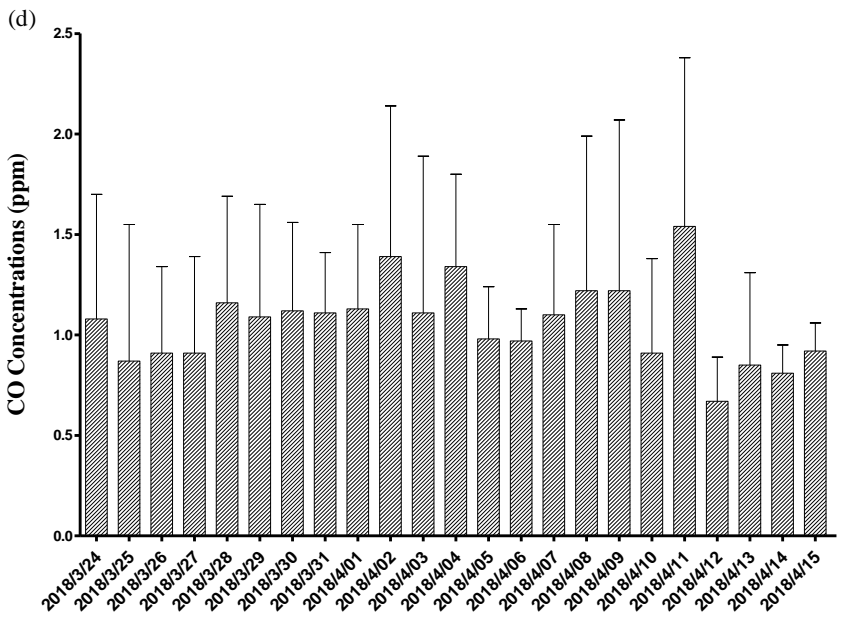

CO concentrations from 3/24 to 4/15 in 2018 .

Fig. 2. (a) Levels of ozone $\left(\mathrm{O}_{3}\right)$, (b) sulfur dioxide $\left(\mathrm{SO}_{2}\right)$, (c) nitrogen dioxide $\left(\mathrm{NO}_{2}\right)$, and (d) carbon monoxide (CO) from Mar 24, 2018 to April 15, 2018 in the Tungdai air monitor site.

scenario. The incubation temperature of the present study in the C. elegans model was $22^{\circ} \mathrm{C}$. According to Petrella (2014), temperature may affect the worm laying eggs if the incubation temperature is higher than $20^{\circ} \mathrm{C}$. Previous studies showed the brood size number between 250 and 300 in the incubation at $20^{\circ} \mathrm{C}$ in the control group (Zhao et al., 2014; Wang et al., 2019). It is worth noting that the incubation temperature of $22^{\circ} \mathrm{C}$ in the present study made it easy to account the brood size number compared with that of $20^{\circ} \mathrm{C}$ due to low number of brood size at $22^{\circ} \mathrm{C}$. The results of the brood size numbers in this study is inconsistent with those of two previous studies (Zhao et al., 2014; Wang et al., 2019), particularly for treatment with the toxicants like $\mathrm{PM}_{2.5}$, indicating that the incubating temperature was an important factor which influenced the variation of brood size.

\section{Effects of TRAP PM2.5 on the Locomotion Behavior of C. elegans}

The locomotion assay was performed to investigate the neurological toxicity of TRAP $\mathrm{PM}_{2.5}$ and analyze the endpoints of neurobehavior, such as body bending and head thrashing. Highly significant dose-dependent reductions of the head thrashing and body bending of nematodes were observed after subjecting the worms to the $\mathrm{PM}_{2.5}$ of Day A (Figs. 5(a1) and 5(a2), respectively). Similar results were also found for the nematodes after exposure to the Days B and $\mathrm{CPM}_{2.5}$ samples with different concentrations (Figs. 5(b1), 5(b2), 5(c1), and 5(c2), respectively). The results presented that the higher the $\mathrm{PM}_{2.5}$ concentrations was, the more likely the motor neurons of the exposed nematodes were affected by the TRAP PM 2.5 . Even at the lowest concentration (1.29 or $\left.1.67 \mathrm{~g} \mathrm{~L}^{-1}\right), \mathrm{PM}_{2.5}$ still negatively affected the head thrashing and body bending of Days A and $\mathrm{C}$ samples although it did not show significant result for the body bending endpoint for Day B sample (the lowest dose $=0.734 \mathrm{~g} \mathrm{~L}^{-1}$ ). Also, the body bending values of the nematodes after exposure at the highest $\mathrm{PM}_{2.5}$ concentrations of Days $\mathrm{A}, \mathrm{B}$, and $\mathrm{C}$ were significantly reduced by more than $50 \%$ compared with those after exposure at the control. According to our previous study (Chung et al., 2019), there was an obvious reduction 

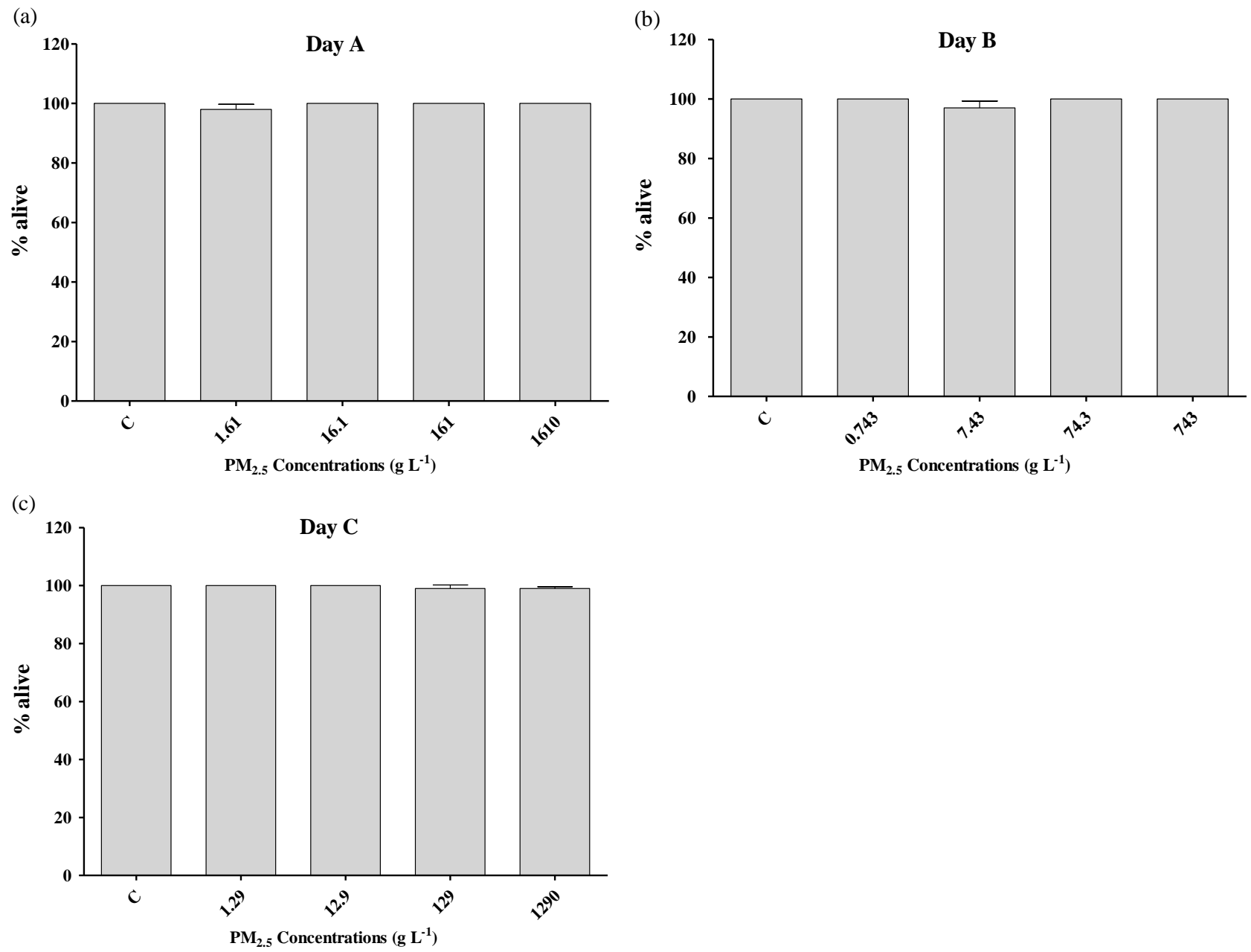

Fig. 3. Survival rates of $C$. elegans after $24 \mathrm{~h}$ exposure to heavily TRAP PM 2.5 obtained by selected three days (Days (a) A, (b) B, and (c) C).

in the head thrashing movement and body bending ability of the nematodes after they had acutely exposed to ambient $\mathrm{PM}_{2.5}$ samples collected from a rural area, implying that a higher exposure level was negatively correlated with the disruption of the neurosensory system of $C$. elegans. Moreover, the prolonged exposure to $\mathrm{PM}_{2.5}$ (concentrations ranging from 0.1 or 1.0 to $100 \mathrm{mg} \mathrm{L}^{-1}$ ) had rendered more toxicity on the locomotion behavior of the nematodes as compared to the acute exposure which only the highest $\mathrm{PM}_{2.5}$ concentration of 10 or $100 \mathrm{mg} \mathrm{L}^{-1}$ resulted in an altered locomotion (Zhao et al., 2014; Sun et al., 2015; Yang et al., 2016). Similarly, two studies proposed that the prolonged exposure to 1 or $100 \mathrm{mg} \mathrm{L}^{-1}$ of coal combustion related $\mathrm{PM}_{2.5}$ could induce significant reductions on the head thrash and body bending of the nematodes (Sun et al., 2015, Wu et al., 2017). In this study, the nematodes with acute exposure to extremely high levels of TRAP $\mathrm{PM}_{2.5}$ from 0.743 to $1290 \mathrm{~g} \mathrm{~L}^{-1}$ also showed consistent results with those of some previous reports (Zhao et al., 2014; Sun et al., 2015; Yang et al., 2016), supporting the fine particulate disrupted behavior of head thrashing and body bending for C. elegans after their acute exposure to high levels of TRAP and coal combustion related $\mathrm{PM}_{2.5}$.

\section{Effects of TRAP PM 2.5 on the Life Span of C. elegans}

The lifespan or ageing of nematodes is an important toxicological endpoint for assessing the long term effects of the different concentrations of TRAP $\mathrm{PM}_{2.5}$ obtained by Days A, B, and C. The three days' samples were pooled together before the test. The expected lifespan of a nematode is usually 24 days. The nematodes exposed to varying concentrations $\left(1.21,12.1,121\right.$, and $\left.1210 \mathrm{~g} \mathrm{~L}^{-1}\right)$ of $\mathrm{PM}_{2.5}$ had smaller survival rates (Fig. 6(a)). The trend of survival rate data in the present study is in agreement with those of previous studies which linked $\mathrm{PM}_{2.5}$ concentration with the decreasing population of exposed nematodes (Zhao et al., 2014; Sun et al., 2015, 2016; Chung et al., 2019; Wang et al., 2019; Zhao et al., 2019). Sun et al. (2015) also reported that acute exposure of $C$. elegans to coal combustion related$\mathrm{PM}_{2.5}$ at $100 \mathrm{mg} \mathrm{L}^{-1}$ significantly decreased the population of the exposed nematodes.

The nematodes exposed to varying concentrations (1.21, 12.1, 121, and $1210 \mathrm{~g} \mathrm{~L}^{-1}$ ) of $\mathrm{PM}_{2.5}$ also exhibited shorter lifespans as compared to the control ones (Figs. 6(b)-6(e)). The results were similar to that of one our previous report (Chung et al., 2019), revealing that the highest concentrations of ambient $\mathrm{PM}_{2.5}$ from rural areas (Chung et al., 2019) and 

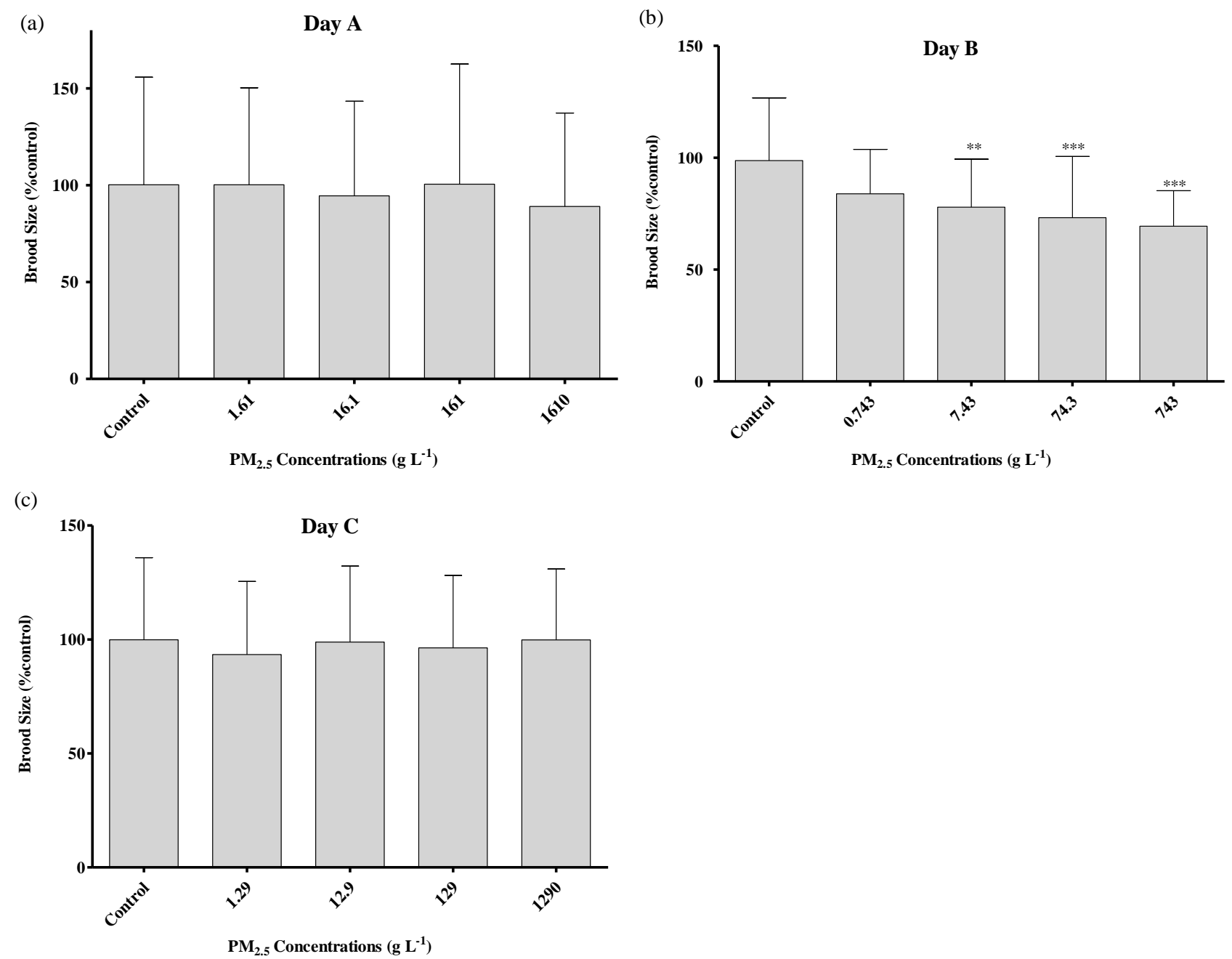

Fig. 4. Reproductive effects of brood sizes in the C. elegans models after 24-hr exposure to heavily TRAP PM 2.5 obtained by selected three days (Days (a) A, (b) B, and (c) C).

the $\mathrm{PM}_{2.5}$ with various concentrations in the present study significantly accelerated the ageing of the nematodes to have lifespans shorter than their typical ones. Zhao et al. (2019) indicated that ambient $\mathrm{PM}_{2.5}$ on a college campus at the concentrations of 10 and $100 \mathrm{mg} \mathrm{L}^{-1}$ caused the oxidative stress activation, increased metabolic enzyme response, induced unfold protein response (UPR), and decreased the lifespan of the nematodes. Furthermore, the antioxidant, such as $\mathrm{N}$-acetylcysteine, could be treated in C. elagans to suppress the oxidative stress from UPR and then to recovery the lifespan attenuation induced by fine particulate (Zhao et al., 2019).

In comparison with that of the control (24 days), the longest lifespans of the nematodes with acute exposure to $\mathrm{PM}_{2.5}$ of $1.21,12.1,121$, and $1210 \mathrm{~g} \mathrm{~L}^{-1}$ were shortened to $20,18,17$, and 16 days, respectively. For the mean lifespan, the nematodes in the control groups performed a significantly longer mean lifespan (14.2 \pm 0.577 days) compared with the those after exposure to TRAP $\mathrm{PM}_{2.5}(11.0 \pm 0.500,9.50 \pm$ $0.860,9.67 \pm 0.289,9.33 \pm 0.287$ days at $1.21,12.1,121$, $1210 \mathrm{~g} \mathrm{~L}^{-1}$, respectively) (Fig. 6(b)). Some previous studies addressed that no significant differences in mean or median lifespans were presented for the nematodes exposed to a low $\mathrm{PM}_{2.5}$ concentration $\left(0.1\right.$ or $\left.1 \mathrm{mg} \mathrm{L}^{-1}\right)$, but untreated nematodes had significantly longer lifespans compared with the nematodes exposed to the $\mathrm{PM}_{2.5}$ concentration of 10.0 or $100 \mathrm{mg} \mathrm{L}^{-1}$ (Zhao et al., 2014; Sun et al., 2015, 2016; Zhao et al., 2019). The days for the $50^{\text {th }}, 25^{\text {th }}$, and $5^{\text {th }}$ percentile of survival rates (or the $50^{\text {th }}, 75^{\text {th }}$, and $95^{\text {th }}$ percentile death days in Figs. 6(c)-6(e), respectively) also showed that the nematodes exposed to TRAP $\mathrm{PM}_{2.5}$ had the shorter percentile death days than those of the untreated nematodes. The $50^{\text {th }}, 75^{\text {th }}$, $95^{\text {th }}$ percentile death day were expressed as the distribution of survival rates for the untreated and treated $\mathrm{PM}_{2.5}$ nematodes. This information is very important for the descriptive statistics of survival rates and death days. Compared with untreated nematodes, $50^{\text {th }}$ and $75^{\text {th }}$ percentile death days didn't have larger change in the treated models in Figs. 6(c) and $6(\mathrm{~d})$. It was worth observing that $95^{\text {th }}$ percentile death days of the treated models were notably and significantly decreased compared with that of the untreated model.

The $C$. elegans were treated with the high levels of TRAP $\mathrm{PM}_{2.5}$ in the present study. $\mathrm{PM}_{2.5}$-bounded contaminants are diverse and variant up to the sources. Yang et al. (2016) 

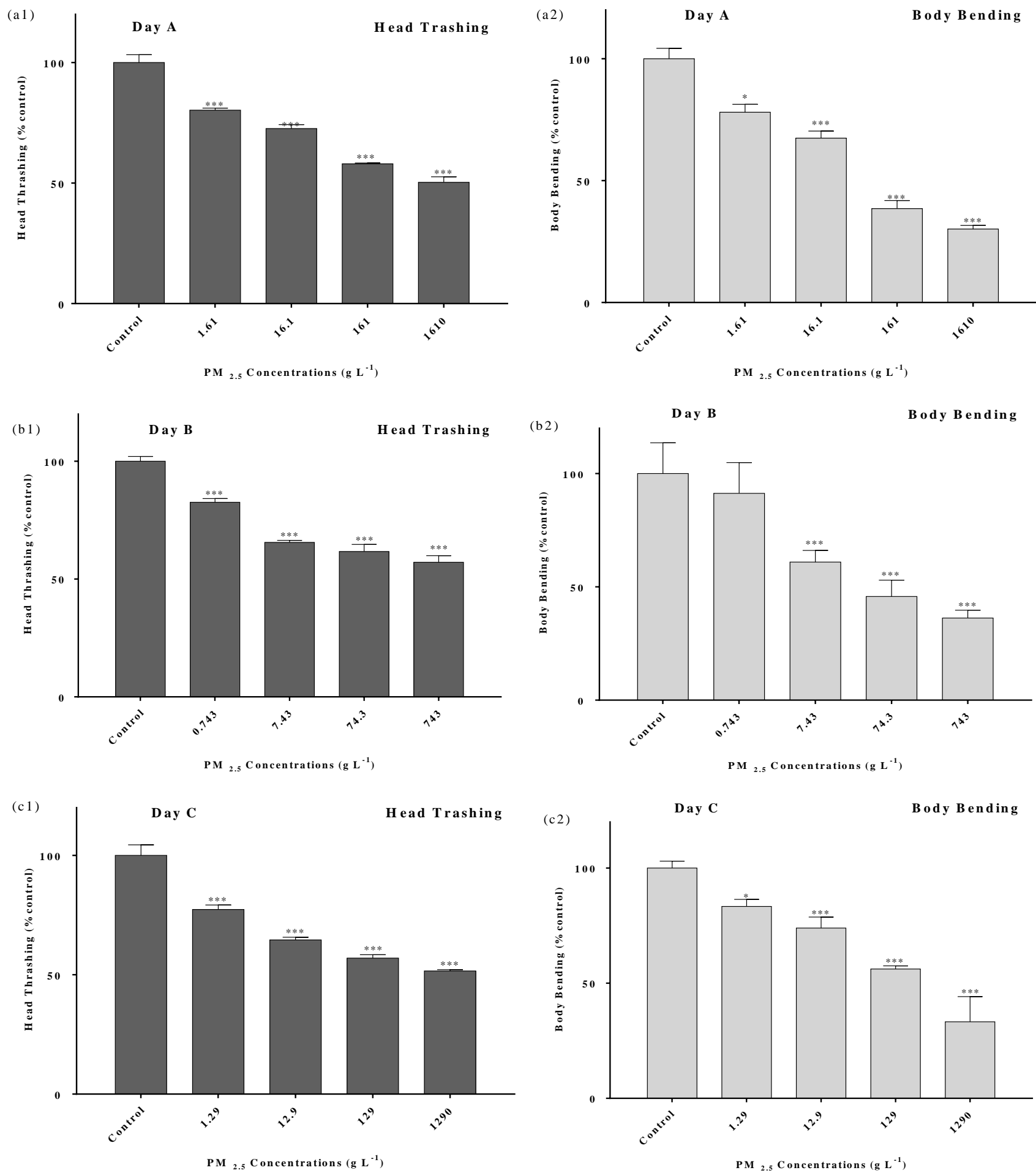

Fig. 5. Dose-dependent reductions of locomotion ((1) head thrashing and (2) body bending) in the C. elegans models after 24-hr exposure to heavily TRAP PM 2.5 obtained in selected three days ((a1 and a2) Days A, (b1 and b2) B, and (c1 and c2) C).

indicated that nematodes with acute exposure to the ambient $\mathrm{PM}_{2.5}$ collected during the Chinese Spring Festival in Beijing at a level of $10 \mathrm{mg} \mathrm{L}^{-1}$ as well as prolonged exposure to those of $0.100-100 \mathrm{mg} \mathrm{L}^{-1}$ disrupted their locomotion behavior and generated the obvious activation of ROS production in the nematodes' intestine. According to our previous study (Chung et al., 2019), $\mathrm{PM}_{2.5}$ with concentrations of 2.5 to $4.5 \mu \mathrm{g} \mathrm{Nm} \mathrm{Nm}^{-3}$ collected in rural areas, caused the neurobehavioral toxicity of nematodes at the low level of 0.115 or $0.144 \mathrm{mg} \mathrm{L}^{-1}$. For the C. elegans models, fine particulate is probably more sensitive to neurological development compared with reproductive development and lifespan. Most published articles addressed to treatment with $\mathrm{PM}_{2.5}$ in C. elegans models at the concentrations of 10.0 or $100 \mathrm{mg} \mathrm{L}^{-1}$ 

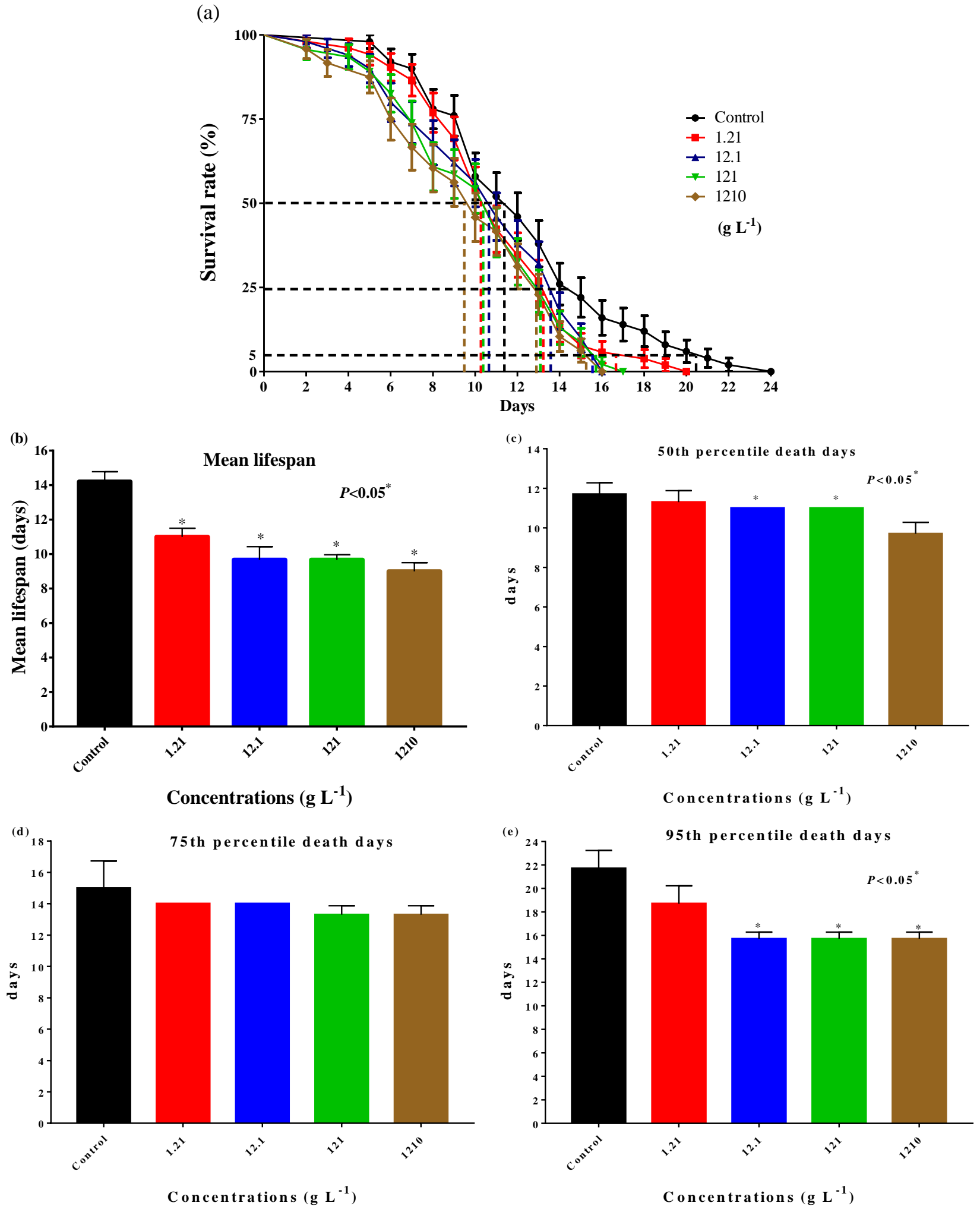

Fig. 6. (a) Survival rates (\%), (b) mean lifespans, (c) $50^{\text {th }}$ percentile death days, (d) $75^{\text {th }}$ percentile death days, and (e) $95^{\text {th }}$ percentile death days of $C$. elegans after $24-\mathrm{hr}$ exposure to heavily TRAP PM 2.5 obtained by selected three days (a mixture of Days A, B, and C).

to present the disrupting effects of neurodevelopment, reproduction, lifespan, oxidative stress activation, and metabolic enzyme response (Zhao et al., 2014; Sun et al.,
2015, 2016; Zhao et al., 2019). The nematodes exposed to extremely high levels of TRAP PM $_{2.5}$ (e.g., $1610 \mathrm{~g} \mathrm{~L}^{-1}$ ) didn't cause the acute toxicity based on our results. It is 
interesting to examine whether the adverse effects of head thrashing, body bending, brood size, and lifespan were affected after the nematodes were exposed to high concentrations of TRAP $\mathrm{PM}_{2.5}$. According to our results, it was showed that high levels of TRAP $\mathrm{PM}_{2.5}$ obviously disrupted the neurological and reproductive function and lifespan in the $C$. elegans models. Furthermore, the severe TRAP pollution was found in Figs. 1 and 2. For the epidemiological studies, it is demonstrated that TRAP species caused the adverse health effects, but their composition and distribution are complicated. It is very difficult to distinguish what kind of the air pollutants or aerosol affect the adverse effects. Although the concentrations of TRAP species were variant and severe in the present study, it makes it clear to show the toxic effects for the nematodes by treating $\mathrm{PM}_{2.5}$ model. Our result might be reflected to the epidemiological studies. The negative impacts of $\mathrm{PM}_{2.5}$ on environmental organisms may eventually lead to probable health risk to humans. Further studies are still needed in order to assess whether the impact of $\mathrm{PM}_{2.5}$ on environmental organisms such as the C. elegans is the same to that on human health.

\section{CONCLUSIONS}

Heavy TRAP PM 2.5 can disrupt multiple toxic endpoints such as locomotion, reproduction, and lifespan in the in-vivo model C. elegans. The locomotion and reproduction of tested nematodes were negatively affected by TRAP PM $\mathrm{P}_{2.5}$. TRAP $\mathrm{PM}_{2.5}$ entered the body to cause adverse effects specially for the systematic effects, such as locomotion and reproduction, indicating the possible deterioration of secondary targeted organs (neurological or reproductive system) of the nematodes. Also, the lifespans of the nematodes dramatically decreased after it was exposed to the TRAP PM $_{2.5}$ compared with those in the untreated ones. Therefore, heavy TRAP $\mathrm{PM}_{2.5}$ could shorten the nematodes' lifespan.

\section{ACKNOWLEDGEMENTS}

This study was supported by the grants from the Ministry of Science and Technology (MOST 106-2221-E-020-001MY3) and Kaohsiung Veterans General Hospital Pingtung Branch (VHCL-108002). We thanked to Professor HowRan Chao and his undergraduate and master students in the Department of Environmental Science and Engineering, National Pingtung University of Science and Technology (ESE/NPUST) with assistance of study design, sampling schedule, sampling processes, and sample extraction. We acknowledge Mr. Ying-Jhih Syu in ESE/NPUST for assisting us to maintain, culture, and test $C$. elegans. We also want to thank Miss Chia-Jung Yen from the Kaohsiung Medical University for assisting us in performing the $C$. elegans experiments. We would also like to thank Dr. Chang-Shi Chen at the National Cheng Kung University for his advice and help in attaining the $C$. elegans culture.

\section{DISCLAIMER}

The authors of this paper declare no conflict of interest.

\section{REFERENCES}

Brenner, S. (1974). The genetics of Caenorhabditis elegans. Genetics 77: 71-94.

Brown, S.G., Penfold, B., Mukherjee, A., Landsberg, K. and Eisinger, D.S. (2019). Conditions leading to elevated $\mathrm{PM}_{2.5}$ at near-road monitoring sites: Case studies in Denver and Indianapolis. Int. J. Environ. Res. Public Health 16: 1634. https://doi.org/10.3390/ijerph16091634

Brucker, N., Moro, A.M., Charão, M.F., Durgante, J., Freitas, F., Baierle, M., Nascimento, S., Gauer, B., Bulcão, R.P., Bubols, G.B., Ferrari, P.D., Thiesen, F.V., Gioda, A., Duarte, M.M.M.F., de Castro, I., Saldiva, P.H. and Garcia, S.C. (2013). Biomarkers of occupational exposure to air pollution, inflammation and oxidative damage in taxi drivers. Sci. Total Environ. 463-464: 884893. https://doi.org/10.1016/j.scitotenv.2013.06.098

Burnett, R.T., Pope III, C.A., Ezzati, M., Olives, C., Lim, S.S., Mehta, S., Shin, H.H., Singh, G., Hubbell, B., Brauer, M., Anderson,H.R., Smith, K.R., Balmes, J.R., Bruce, N.G., Kan, H., Laden, F., Prüss-Ustün, A., Turner, M.C., Gapstur, S.M., ... Cohen, A. (2014). An integrated risk function for estimating the global burden of disease attributable to ambient fine particulate matter exposure. Environ. Health Perspect. 122: 397-403. https://doi.org/1 0.1289/ehp.1307049

Chao, H.R., Hsu, J.W., Ku, H.Y., Wang, S.L., Huang, H.B., Liou, S.H. and Tsou, T.C. (2018). Inflammatory response and $\mathrm{PM}_{2.5}$ exposure of urban traffic conductors. Aerosol Air Qual. Res. 18: 2633-2642. https://doi.org/10.4209/aa qr.2018.04.0132

Chen, H., Burnett, R.T., Kwong, J.C., Villeneuve, P.J., Goldberg, M.S., Brook, R.D., van Donkelaar, A., Jerrett, M., Martin, R.V., Brook, J.R. and Copes, R. (2013). Risk of incident diabetes in relation to long-term exposure to fine particulate matter in Ontario, Canada. Environ. Health Perspect. 121: 804-810. https://doi.org/10.1289/e hp. 1205958

Choi, J.H., Kim, J.S., Kim, Y.C., Kim, Y.S., Chung, N.H. and Cho, M.H. (2004). Comparative study of $\mathrm{PM}_{2.5}$-and $\mathrm{PM}_{10^{-}}$ induced oxidative stress in rat lung epithelial cells. $J$. Vet. Sci. 5: 11-18. https://doi.org/10.4142/jvs.2004.5.1.11

Chung, M.C., Tsai, M.H., Que, D.E., Bongo, S.J., Hsu, W.L., Tayo, L.L., Lin, Y.H., Lin, S.L., Gou, Y.Y., Hsu, Y.C., Hou, W.C., Huang, K.L. and Chao, H.R. (2019). Fine particulate matter-induced toxic effects in an animal model of caenorhabditis elegans. Aerosol Air Qual. Res. 19: 1068-1078. https://doi.org/10.4209/aaqr.2019.03.0127

Crouse, D.L., Peters, P.A., van Donkelaar, A., Goldberg, M.S., Villeneuve, P.J., Brion, O., Khan, S., Atari, D.O., Jerrett, M., Pope III, C.A., Brauer, M., Brook, J.R., Martin, R.V., Stieb, D. and Burnett, R.T. (2012). Risk of nonaccidental and cardiovascular mortality in relation to long-term exposure to low concentrations of fine particulate matter: A Canadian national-level cohort study. Environ. Health Perspect. 120: 708-714. https://doi.org/10.1289/e hp. 1104049

El-Hajj, Z.W. and Newman, E.B. (2015). An escherichia coli mutant that makes exceptionally long cells. J. Bacteriol. 
197: 1507-1514. https://doi.org/10.1128/JB.00046-15

Elliott, C.T. and Copes, R. (2011). urden of mortality due to ambient fine particulate air pollution $\left(\mathrm{PM}_{2.5}\right)$ in interior and Northern BC. Can. J. Public Health 102: 390-393. https://doi.org/10.1007/BF03404182

Fann, N., Lamson, A.D., Anenberg, S.C., Wesson, K., Risley, D. and Hubbell, B.J. (2012). Estimating the national public health burden associated with exposure to ambient $\mathrm{PM}_{2.5}$ and ozone. Risk Anal. 32: 81-95. https://doi.org/10.1111/j.1539-6924.2011.01630.x

Hayes, R.B., Lim, C., Zhang, Y., Cromar, K., Shao, Y., Reynolds, H.R., Silverman, D.T., Jones, R.R., Park, Y. Jerrett, M., Ahn, J. and Thurston, G.D. (2019). PM $_{2.5}$ air pollution and cause-specific cardiovascular disease mortality. Int. J. Epidemiol. 49: 25-35. https://doi.org/10. 1093/ije/dyz114

Health Effects Institute (HEI) (2018). State of global air. https://www.stateofglobalair.org/sites/default/files/soga2018-report.pdf

Hodgkin, J. and Barnes, T.M. (1991). More is not better: Brood size and population growth in a self-fertilizing nematode. Proc. Royal Soc. B 246: 19-24. https://doi.org/ 10.1098/rspb.1991.0119

Hu, Z. (2009). Spatial analysis of modis aerosol optical depth, $\mathrm{PM}_{2.5}$, and chronic coronary heart disease. Int. J. Health Geographics 8: 27. https://doi.org/10.1186/1476072X-8-27

Jiang, N., Liu, X., Wang, S., Yu, X., Yin, S., Duan, S., Wang, S., Zhang, R. and Li, S. (2019). Pollution characterization, source identification, and health risks of atmosphericparticle-bound heavy metals in $\mathrm{PM}_{10}$ and $\mathrm{PM}_{2.5}$ at multiple sites in an emerging megacity in the Central region of China. Aerosol Air Qual. Res. 19: 247-271. https://doi.org/10.4209/aaqr.2018.07.0275

Kinney, P.L., Gichuru, M.G., Volavka-Close, N., Ngo, N., Ndiba, P.K., Law, A., Gachanja, A., Gaita, S.M., Chillrud, S.N. and Sclar, E. (2011). Traffic impacts on $\mathrm{PM}_{2.5}$ air quality in Nairobi, Kenya. Environ. Sci. Policy 14: 369378. https://doi.org/10.1016/j.envsci.2011.02.005

Kloog, I., Melly, S.J., Ridgway, W.L., Coull, B.A. and Schwartz, J. (2012). Using new satellite based exposure methods to study the association between pregnancy $\mathrm{PM}_{2.5}$ exposure, premature birth and birth weight in Massachusetts. Environ. Health Perspect. 11: 40. https://doi.org/10.1186/1476-069X-11-40

Labrada-Delgado, G., Aragon-Pina, A., Campos-Ramos, A., Castro-Romero, T., Amador-Munoz, O. and VillalobosPietrini, R. (2012). Chemical and morphological characterization of $\mathrm{PM}_{2.5}$ collected during MILAGRO campaign using scanning electron microscopy. Atmos. Pollut. Res. 3: 289-300. https://doi.org/10.5094/APR.201 2.032

Li, R., Zhou, R. and Zhang, J. (2018). Function of $\mathrm{PM}_{2.5}$ in the pathogenesis of lung cancer and chronic airway inflammatory diseases. Oncol. Lett. 15: 7506-7514. https://doi.org/10.3892/ol.2018.8355

Lisetskii, F. and Borovlev, A. (2019). Monitoring of emission of particulate matter and air pollution using lidar in Belgorod, Russia. Aerosol Air Qual. Res. 19: 504-515. https://doi.org/10.4209/aaqr.2017.12.0593

Lu, H.Y., Wu, Y.L., Mutuku, J.K. and Chang, K.H. (2019). Various sources of $\mathrm{PM}_{2.5}$ and their impact on the air quality in Tainan City, Taiwan. Aerosol Air Qual. Res. 19: 601-619. https://doi.org/10.4209/aaqr.2019.01.0024

McMullen, P.D., Aprison, E.Z., Winter, P.B., Amaral, L.A., Morimoto, R.I. and Ruvinsky, I. (2012). Macro-level modeling of the response of $C$. elegans reproduction to chronic heat stress. PLoS Comput. Biol. 8: e1002338. https://doi.org/10.1371/journal.pcbi.1002338

Min, K.D., Yi, S.J., Kim, H.C., Leem, J.H., Kwon, H.J., Hong, S., Kim, K.S. and Kim, S.Y. (2020). Association between exposure to traffic-related air pollution and pediatric allergic diseases based on modeled air pollution concentrations and traffic measures in Seoul, Korea: A comparative analysis. Environ. Health Perspect. 19: 6. https://doi.org/10.1186/s12940-020-0563-6

Moon, J., Kwak, J.I. and An, Y.J. (2019). The effects of silver nanomaterial shape and size on toxicity to Caenorhabditis elegans in soil media. Chemosphere 215: 50-56. https://doi.org/10.1016/j.chemosphere.2018.09.177

Morgenstern, V., Zutavern, A., Cyrys, J., Brockow, I., Koletzko, S., Kramer, U., Behrendt, H., Herbarth, O., von Berg, A., Bauer, C.P., Wichmann, H.E. and Heinrich, J. (2008). Atopic diseases, allergic sensitization, and exposure to traffic-related air pollution in children. Am. J. Respir. Crit. Care Med. 177: 1331-1337. https://doi.org/1 0.1164/rccm.200701-036OC

Nass, R. and Hamza, I. (2007). The nematode C. elegans as an animal model to explore toxicology in vivo: Solid and axenic growth culture conditions and compound exposure parameters. Curr. Protoc. Toxicol. 31: 1.9.1-1.9.18. https://doi.org/10.1002/0471140856.tx0109s31

Nouara, A., Wu, Q., Li, Y., Tang, M., Wang, H., Zhao, Y. and Wang, D. (2013). Carboxylic acid functionalization prevents the translocation of multi-walled carbon nanotubes at predicted environmentally relevant concentrations into targeted organs of nematode Caenorhabditis elegans. Nanoscale 5: 6088-6096. https://doi.org/10.1039/C3NR0 0847A

Oh, S.M., Kim, H.R., Park, Y.J., Lee, S.Y. and Chung, K.H. (2011). Organic extracts of urban air pollution particulate matter $\left(\mathrm{PM}_{2.5}\right)$-induced genotoxicity and oxidative stress in human lung bronchial epithelial cells (BEAS-2B cells). Mutat. Res. Genet. Toxicol. Environ. Mutagen. 723: 142151. https://doi.org/10.1016/j.mrgentox.2011.04.003

Orru, H., Maasikmets, M., Lai, T., Tamm, T., Kaasik, M., Kimmel, V., Orru, K., Merisalu, E. and Forsberg, B. (2011). Health impacts of particulate matter in five major Estonian. towns: Main sources of exposure and local differences. Air Qual Atmos Health 4: 247-258. https://doi.org/10.1007/s11869-010-0075-6

Petrella, L.N. (2014). Natural variants of C. elegans demonstrate defects in both sperm function and oogenesis at elevated temperatures. PLoS One. 9: e112377. https://doi.org/10.1371/journal.pone.0112377

Sohlenius, B. (1980). Abundance, biomass and contribution to energy flow by soil nematodes in terrestrial ecosystems. Oikos 34: 186-194. https://www.jstor.org/stable/3544181 
Sun, L., Lin, Z., Liao, K., Xi, Z. and Wang, D. (2015). Adverse effects of coal combustion related fine particulate matter $\left(\mathrm{PM}_{2.5}\right)$ on nematode Caenorhabditis elegans. Sci. Total Environ. 512-513: 251-260. https://doi.org/10.1016 /j.scitotenv.2015.01.058

Sun, L., Wu, Q., Liao, K., Yu, P., Cui, Q., Rui, Q. and Wang, D. (2016). Contribution of heavy metals to toxicity of coal combustion related fine particulate matter $\left(\mathrm{PM}_{2.5}\right)$ in Caenorhabditis elegans with wild-type or susceptible genetic background. Chemosphere 144: 2392-2400. https://doi.org/10.1016/j.chemosphere.2015.11.028

Wang, S., Chu, Z., Zhang, K. and Miao, G. (2018). Cadmium-induced serotonergic neuron and reproduction damages conferred lethality in the nematode Caenorhabditis elegans. Chemosphere 213: 11-18. https://doi.org/10.101 6/j.chemosphere.2018.09.016

Wang, Y., Ding, D., Shu, M., Wei, Z., Wang, T., Zhang, Q., Ji, X., Zhou, P. and Dan, M. (2019). Characteristics of indoor and outdoor fine phthalates during different seasons and haze periods in Beijing. Aerosol Air Qual Res. 19: 364-374. https://doi.org/10.4209/aaqr.2018.03.0114

Williams, A.M., Phaneuf, D.J., Barrett, M.A. and Su, J.G. (2019). Short-term impact of $\mathrm{PM}_{2.5}$ on contemporaneous asthma medication use: Behavior and the value of pollution reductions. Proc. Natl. Acad. Sci. U.S.A. 116: 5246-5253. https://doi.org/10.1073/pnas.1805647115

World Health Organization (WHO) (2005). Air quality guidelines. Global update 2005. Particulate matter, ozone, nitrogen dioxide and sulfur dioxide. https://www.euro.wh o.int/en/health-topics/environment-and-health/air-quality /publications/pre2009/air-quality-guidelines.-global-update2005.-particulate-matter,-ozone,-nitrogen-dioxide-and-su lfur-dioxide

World Health Organization (WHO) (2016). Ambient air pollution: A global assessment of exposure and burden of disease. https://www.who.int/phe/publications/air-polluti on-global-assessment/en/

Wu, Q., Han, X., Wang, D., Zhao, F. and Wang, D. (2017). Coal combustion related fine particulate matter $\left(\mathrm{PM}_{2.5}\right)$ induces toxicity in Caenorhabditis elegans by dysregulating microRNA expression. Toxicol. Res. 6: 432-441. https://doi.org/10.1039/c7tx00107j

Xiang, S., Yu, Y.T., Hu, Z. and Noll, K.E. (2019). Characterization of dispersion and ultrafine-particle emission factors based on near-roadway monitoring Part I: Light duty vehicles. Aerosol Air Qual Res. 19: 2410 2420. https://doi.org/10.4209/aaqr.2019.08.0386

Xing, W., Zhang, L., Yang, L., Zhou, Q., Zhang, X., Toriba, A., Hayakawa, K. and Tang, N. (2020). Characteristics of $\mathrm{PM}_{2.5}$-bound polycyclic aromatic hydrocarbons and nitropolycyclic aromatic hydrocarbons at a roadside air pollution monitoring station in Kanazawa, Japan. Int. J.
Environ. Res. Public Health 17: 805. https://doi.org/10.33 90/ijerph17030805

Yang, R., Rui, Q., Kong, L., Zhang, N., Li, Y., Wang, X., Tao, J., Tian, P., Ma, Y., Wei, J., Li, G. and Wang, D. (2016). Metallothioneins act downstream of insulin signaling to regulate toxicity of outdoor fine particulate matter $\left(\mathrm{PM}_{2.5}\right)$ during Spring Festival in Beijing in nematode Caenorhabditis elegans. Toxicol. Res. 5: 10971105. https://doi.org/10.1039/c6tx00022c

Yang, Z., Xue, K.S., Sun, X., Williams, P.L., Wang, J.S. and Tang, L. (2018). Toxicogenomic responses to zearalenone in Caenorhabditis elegans reveal possible molecular mechanisms of reproductive toxicity. Food Chem. Toxicol. 122: 49-58. https://doi.org/10.1016/j.fct.2018.09.040

Yue, W., Li, X., Liu, J., Li, Y., Yu, X., Deng, B., Wan, T., Zhang, G., Huang, Y., He, W., Hua, W., Shao, L., Li, W. and Yang, S. (2006). Characterization of $\mathrm{PM}_{2.5}$ in the ambient air of Shanghai city by analyzing individual particles. Sci. Total Environ. 368: 916-925. https://doi.org/ 10.1016/j.scitotenv.2006.03.043

Zanobetti, A., Dominici, F., Wang, Y. and Schwartz, J.D. (2014). A national case-crossover analysis of the shortterm effect of $\mathrm{PM}_{2.5}$ on hospitalizations and mortality in subjects with diabetes and neurological disorders. Environ Health 13: 38. https://doi.org/10.1186/1476-069X-13-38

Zhao, J., Gao, Z., Tian, Z., Xie, Y., Xin, F., Jiang, R., Kan, H. and Song, W. (2013). The biological effects of individual-level $\mathrm{PM}_{2.5}$ exposure on systemic immunity and inflammatory response in traffic policemen. Occup. Environ. Med. 70: 426-431. http://doi.org/10.1136/oemed2012-100864

Zhao, Y., Lin, Z., Jia, R., Li, G., Xi, Z. and Wang, D. (2014). Transgenerational effects of traffic-related fine particulate matter $\left(\mathrm{PM}_{2.5}\right)$ on nematode Caenorhabditis elegans. J. Hazard. Mater. 274: 106-114. https://doi.org/10.1016/j.jh azmat.2014.03.064

Zhao, Y., Wang, X., Wu, Q., Li, Y., Tang, M. and Wang, D. (2015). Quantum dots exposure alters both development and function of D-type GABAergic motor neurons in nematode Caenorhabditis elegans. Toxicol. Res. 4: 399408. https://doi.org/10.1039/C4TX00207E

Zhao, Y., Jin, L., Chi, Y., Yang, J., Zhen, Q. and Wu, H. (2019). Fine particulate matter leads to unfolded protein response and shortened lifespan by inducing oxidative stress in C. elegans. Oxid. Med. Cell. Longevity 2019: 2492368. https://doi.org/10.1155/2019/2492368

Received for review, May 3, 2020 Revised, June 1, 2020 Accepted, June 3, 2020 